OPEN ACCESS

Citation: Ruonan Zheng, Shuhua Zhao, Majid Khayatnezhad, Sayed Afzal Shah (2021) Comparative study and genetic diversity in Salvia (Lamiaceae) using RAPD Molecular Markers. Caryologia 74(2): 45-56. doi: 10.36253/caryologia-1236

Received: March 05, 2021

Accepted: April 28, 2021

Published: October 08, 2021

Copyright: (c) 2021 Ruonan Zheng, Shuhua Zhao, Majid Khayatnezhad, Sayed Afzal Shah. This is an open access, peer-reviewed article published by Firenze University Press (http://www.fupress.com/caryologia) and distributed under the terms of the Creative Commons Attribution License, which permits unrestricted use, distribution, and reproduction in any medium, provided the original author and source are credited.

Data Availability Statement: All relevant data are within the paper and its Supporting Information files.

Competing Interests: The Author(s) declare(s) no conflict of interest.

\section{Comparative study and genetic diversity in Salvia (Lamiaceae) using RAPD Molecular Markers}

\author{
Ruonan Zheng ${ }^{1, *}$, Shuhua $Z_{H_{A}{ }^{2}}$, Majid Khayatnezhad ${ }^{3}$, Sayed Afzal \\ $\mathrm{SHAH}^{4}$ \\ ${ }^{1}$ Zhengzhou Railway Vocational and Technical College, Zhengzhou,Henan, 450052, Chi- \\ na \\ ${ }^{2}$ Zhengzhou central hospital, Zhengzhou, Henan, 450007, China \\ ${ }^{3}$ Department of Environmental Sciences and Engineering, Ardabil Branch, Islamic Azad \\ University, Ardabil, Iran \\ ${ }^{4}$ Department of Biological Sciences, National University of Medical Sciences, The Mall, \\ Abid Majeed Road, Rawalpindi, Punjab, 46000, Pakistan \\ *Corresponding Author. E-mail: zhengruonan2021@163.com; majidkhayatnezhad126@ \\ gmail.com
}

\begin{abstract}
Salvia has a high degree of environmental compatibility and is widespread around the world, especially in tropical and temperate regions. It is represented by 61 species including 19 endemic species. Salvia species are mostly shrubs or subshrubs, occasionally herbs, typically perennial, sometimes biennial or annual, and often aromatic. The genus has high medicinal, commercial and horticultural value. It is the largest and one of the taxonomically complicated genus of Lamiaceae. To determine the genetic diversity and understand the species, we produced both morphological and molecular data using 145 randomly collected plants representing 30 species from 18 provinces of Iran. A total of 107 reproducible bands were generated by 10 of 25 random amplified polymorphic DNA (RAPD) primers, with an average of 10.7 bands/ primer and $44 \%$ polymorphism. Largest number of effective alleles (Ne), genetic diversity $(\mathrm{H})$, and Shannon Index (I) were shown by Salvia reuterana. Our data depicted highest similarity between $S$. suffruticosa and S. hydrangea and lowest between $S$. aristata and S. oligphylla. S. limbata showed relatively low level of genetic variation. Finally, the Neighbor Joining (NJ) trees based on RAPD markers data divided the populations into two different clusters, indicating their genetic difference which is discussed in details.
\end{abstract}

Keywords: Gene flow, Genetic Variation, Random Amplified Polymorphic DNA (RAPD), Salvia.

\title{
INTRODUCTION
}

One of the most important aspect of biological diversity for conservation strategies is the genetic diversity, particularly in rare, and narrow endemic species (Mills and Schwartz 2005; Tomasello et al. 2015). Most authors 
agree that longstanding evolutionary potential of a species necessitates maintenance of genetic diversity (Falk and Holsinger 1991). Similarly, most geneticists regard population size as a significant factor in preserving genetic diversity (Ellegren and Galtier 2016; Turchetto et al. 2016). In fragmented populations, this is critical as they are more susceptible due to allelic resources' loss and bigger population differentiation through genetic drift (reduces heterozygosity and subsequent allele fixation) and inbreeding depression (develop homozygosity within populations) (Frankham 2005). Understanding of genetic variability and inter-, and intra-population diversity of rare and endemic species is therefore necessary for their conservation and management (e.g. Cires et al. 2012, 2013; Jing, et al. 2021).

Salvia L. of family Lamiaceae (Mentheae-Salviinae) is recognized as the largest genus, comprising about 1000 species distributed in Central and South America (500 species), Western Asia (200 species), and Eastern Asia (100 species) (Walker et al. 2004; Will and ClaßenBockhoff 2017). Iran is considered one of the major regions for diversity of Salvia in Southwest Asia represented by 19 endemic species out of 61 (Jamzad 2012). The name of the genus 'Salvia' comes from the Latin name 'Salvio' which means to recover or save (Wang et al. 2011). Salvia is one of the groups of herbs most valued for its richness in essential oil and biologically active compounds (Erbano et al. 2015). In industries such as pharmaceuticals, the use of the Salvia has been widely increased since it has pharmacological potentials including anti-inflammatory, and antiplatelet properties (Erbano et al. 2015). Salvia species have been used against different ailments including diabetes, acquired immunodeficiency syndrome (AIDS), liver disease, and Alzheimer's disease (Sepehry Javan et al. 2012). Members of the genus have economical value in the perfumery industry, cosmetics, spices, and flavoring agents (Wang et al. 2011).

Plant genetic diversity is a crucial feature regarding their breeding and domestication. Some researcher have thus attempted to evaluate the variability in various Salvia species using ISSR and RAPD techniques (Song et al. 2010; Wang et al. 2011; Sepehry Javan et al. 2012; Zhang et al., 2013; Peng et al. 2014; Erbano et al. 2015). They have documented high polymorphism in markers data and reported the utility of these techniques for assessing the genetic diversity in Salvia (Song et al. 2010; Javan et al. 2012). Kharazian (2010) studied the taxonomy and morphology of 42 Salvia spinosa L. accessions (Lamiaceae) from Iran. The hair frequency and indumentum of the base and surface of the stem, the shape of the leaf, the leaf margin, and the leaf apex were all linked to the morpho- logical diversity of this species. Cluster analysis revealed that there was variation among the accessions. Hence, its morphological diversity may be attributed to polymorphism, hybridization, and new varieties. (Kharazian 2010, Zou et al. 2019; Niu et al. 2021; Sun et al. 2021).

ISSR and RAPD molecular techniques were used to assess the genetic relationships among twenty-one ecotypes of eight Salvia species in Iran (YousefiazarKhanian et al. 2016). The findings of their marker parameter analysis revealed no significant differences between the two marker systems. ISSR and RAPD markers were shown to have identical efficiency in identifying genetic polymorphisms and a strong ability to distinguish closely related Salvia ecotypes. For genetic diversity and relationship study of nine Salvia species in Iran, Etminan et al., (2018) used inter-simple sequence repeats (ISSR) and start codon targeted (SCoT) markers. Twenty-one ISSR and twenty SCoT primers, amplified 350 and 329 loci, respectively, all of which were polymorphic. The average polymorphism information quality (ISSR, 0.38; SCoT, 0.40), average band informativeness (ISSR, 16.67; SCoT, 16.45), and resolving power (ISSR, 9.75; SCoT, 12.52) found within Salvia accessions demonstrated a high level of genetic diversity. Their findings suggested that SCoT markers can be reliably used to assess genetic diversity and relationships among Salvia species. ISSR is a simple and efficient marker system for identification of genetic diversity for plant germplasm collection (Peng et al. 2014). ISSR molecular markers have been used to show polymorphism and distinguish germplasms of Salvia miltiorrhiza Bunge by incorporating phenotypic characters (Zhang et al. 2013).

Molecular markers are commonly used in genetic analysis, fingerprinting, linkage mapping, germplasm characterization, and molecular breeding. RAPD analysis using PCR along with short arbitrary sequence primers has been reported sensitive to detecting variation at level of individuals (Williams et al. 1990). The benefits of this method are: a) a large number of samples are tested easily and efficiently using less quantity of material; b) the DNA amplicons are independent of ontogenetic expression; c) several genomic regions may be sampled with likely infinite numbers of markers (Soniya et al. 2001; Esfandani-Bozchaloyi et al. 2017 a, 2017b, 2017c, 2017d).

This study has been carried out to evaluate the genetic diversity and relationships among the Iranian Salvia species based on RAPD data. This is the first step towards using RAPD markers on a broader sampling of Iranian Salvia and aims at answering the following questions: 1) is there infra- and interspecific genetic diversity among Salvia species? 2) Is genetic distance 
correlated with distribution of these species? 3) What is the populations' genetic structure? 4) Is there any genetic exchange within Salvia species?

\section{MATERIALS AND METHODS}

\section{Plant sampling}

A total of 145 individuals were collected from ecogeographically different populations representing $30 \mathrm{Sal}$ via species in East Azerbaijan, Lorestan, Kermanshah, Guilan, Mazandaran, Golestan, Yazd, Esfahan, Tehran, Arak, Hamadan, Kurdistan, Ilam, Bandar Abbas, Ghazvin, Khorasan and Ardabil Provinces of Iran during July-August 2017-2019 (Table 1; Figure 1). All of these samples were used during RAPD and morphometric analysis and stored for further use in $-20^{\circ} \mathrm{C}$.

\section{Morphological studies}

Three to twelve samples from each species were used for morphometric analysis. A total of 22 morphological (9 qualitative, 13 quantitative) characters were examined. The obtained data were standardized (Mean $=0$, variance $=1$ ) and used to assess Euclidean distance for clustering and ordination analyses (Podani 2000). Morphological characters studied were: basal leaf shape, basal leaf length, basal leaf width, stem leaf length, stem leaf width leaf surface, bract shape, bract length, bract color, pedicel length, calyx length.

Table 1. Voucher details of Salvia species in this study from Iran by khayatnezhad.

\begin{tabular}{|c|c|c|c|c|c|}
\hline No & Sp. & Locality & Latitude & Longitude & $\begin{array}{l}\text { Altitude } \\
(\mathrm{m})\end{array}$ \\
\hline Sp1 & $\begin{array}{l}\text { Salvia aristata } \\
\text { Aucher ex Benth. }\end{array}$ & East Azerbaijan, kaleybar, Shojabad & $38^{\circ} 52^{\prime} 37^{\prime \prime}$ & $47^{\circ} 23^{\prime} 92^{\prime \prime}$ & 1144 \\
\hline $\mathrm{Sp} 2$ & Salvia eremophila Boiss. & Esfahan, Ghameshlou, Sanjab & $32^{\circ} 50^{\prime} 03^{\prime \prime}$ & $51^{\circ} 24^{\prime} 28^{\prime \prime}$ & 1990 \\
\hline $\mathrm{Sp} 3$ & Salvia santolinifolia Boiss. & Fars, Jahrom & $29^{\circ} 20^{\prime} 07^{\prime \prime}$ & $51^{\circ} 52^{\prime} 08^{\prime \prime}$ & 1610 \\
\hline Sp4 & Salvia tebesana Bunge & Khorasan, Tabas & $38^{\circ} 52^{\prime} 373$ & $47^{\circ} 23^{\prime} 92^{\prime \prime}$ & 2234 \\
\hline Sp5 & Salvia bracteata Banks \& Sol & Lorestan, Oshtorankuh, above Tihun village & $33^{\circ} 57^{\prime} 12^{\prime \prime}$ & $47^{\circ} 57^{\prime} 32^{\prime \prime}$ & 2500 \\
\hline Sp6 & Salvia suffruticosa Montb. \& Aucher & Hamedan, Nahavand & $34^{\circ} 52^{\prime} 373$ & $48^{\circ} 23^{\prime} 92^{\prime \prime}$ & 2200 \\
\hline Sp7 & Salvia dracocephaloides Boiss. & East Azerbaijan, kaleybar, Cheshme Ali Akbar & $38^{\circ} 52^{\prime} 373$ & $47^{\circ} 23^{\prime} 92^{\prime \prime}$ & 1144 \\
\hline Sp8 & Salvia hydrangea DC. ex Benth. & Arak, Komayjan, Pass of Chehregan village, the margin road & $35^{\circ} 50^{\prime} 03^{\prime \prime}$ & $51^{\circ} 24^{\prime} 28^{\prime \prime}$ & 1700 \\
\hline Sp9 & Salvia multicaulis Vahl. & Mazandaran, Haraz road, Emam Zad-e-Hashem & $36^{\circ} 14^{\prime} 14^{\prime \prime}$ & $51^{\circ} 18^{\prime} 07^{\prime \prime}$ & 1807 \\
\hline Sp10 & Salvia syriaca $\mathrm{L}$. & Esfahan, Fereydunshahr & $32^{\circ} 36^{\prime} 93^{\prime \prime}$ & $51^{\circ} 27^{\prime} 90^{\prime \prime}$ & 2500 \\
\hline Sp11 & Salvia viridis $\mathrm{L}$. & Guilan, Sangar, Road sid & $37^{\circ} 07^{\prime} 02^{\prime \prime}$ & $49^{\circ} 44^{\prime} 32^{\prime \prime}$ & 48 \\
\hline Sp12 & Salvia mirzayanii Rech. f. \& Esfand. & Boushehr, Dashtestan & $28^{\circ} 57^{\prime} 22^{\prime \prime}$ & $51^{\circ} 28^{\prime} 31^{\prime \prime}$ & 430 \\
\hline Sp13 & Salvia macrosiphon Boiss. & Yazd, Khatam & $30^{\circ} 07^{\prime} 24^{\prime \prime}$ & $53^{\circ} 59^{\prime} 06^{\prime \prime}$ & 2178 \\
\hline Sp14 & S. sharifii Rech. f. \& Esfand. & Bandar Abbas, Hormozgan & $28^{\circ} 57^{\prime} 22^{\prime \prime}$ & $51^{\circ} 28^{\prime} 31^{\prime \prime}$ & 288 \\
\hline Sp15 & Salvia reuterana Boiss. & Hamedan, Alvand & $34^{\circ} 46^{\prime} 10^{\prime \prime}$ & $48^{\circ} 30^{\prime} 00^{\prime \prime}$ & 1870 \\
\hline Sp16 & Salvia palaestina Benth. & Kermanshah, Islamabad & $35^{\circ} 37^{\prime} 77^{\prime \prime}$ & $46^{\circ} 20^{\prime} 25^{\prime \prime}$ & 1888 \\
\hline Sp17 & Salvia sclareopsis Bornm. ex Hedge & Ilam, Ilam & $33^{\circ} 47^{\prime} 60^{\prime \prime}$ & $46^{\circ} 07^{\prime} 58^{\prime \prime}$ & 1250 \\
\hline Sp18 & Salvia spinose $\mathrm{L}$. & Guilan, Lahijan & $37^{\circ} 07^{\prime} 02^{\prime \prime}$ & $49^{\circ} 44^{\prime} 32^{\prime \prime}$ & 48 \\
\hline Sp19 & Salvia compressa Vent. & Bandar Abbas, Hormozgan & $28^{\circ} 57^{\prime} 22^{\prime \prime}$ & $51^{\circ} 28^{\prime} 31^{\prime \prime}$ & 288 \\
\hline $\mathrm{Sp} 20$ & Salvia sclarea $\mathrm{L}$. & Esfahan:, Ghameshlou, Sanjab & $32^{\circ} 36^{\prime} 93^{\prime \prime}$ & $51^{\circ} 27^{\prime} 90^{\prime \prime}$ & 2500 \\
\hline $\mathrm{Sp} 21$ & Salvia aethiopis L. & Azerbaijan, $78 \mathrm{~km}$ from Mianeh to Khalkhl. & $37^{\circ} 38^{\prime} 53^{\prime \prime}$ & $48^{\circ} 36^{\prime} 11^{\prime \prime}$ & 1500 \\
\hline Sp22 & Salvia microstegia Boiss. \& Bal. & Tehran, Darband & $35^{\circ} 36^{\prime} 93^{\prime \prime}$ & $51^{\circ} 27^{\prime} 90^{\prime \prime}$ & 1700 \\
\hline Sp23 & Salvia xanthocheila Boiss. ex Benth. & Ardabil, Khalkhal & $37^{\circ} 38^{\prime} 53^{\prime \prime}$ & $48^{\circ} 36^{\prime} 11^{\prime \prime}$ & 1958 \\
\hline Sp24 & Salvia limbata C. A. Mey. & Guilan,Gole rodbar, Road sid & $37^{\circ} 09^{\prime} 45^{\prime \prime}$ & $49^{\circ} 55^{\prime} 39^{\prime \prime}$ & 15 \\
\hline Sp25 & Salvia chloroleuca Rech. f. \& Aell. & Golestan, Ramian & $37^{\circ} 09^{\prime} 45^{\prime \prime}$ & $55^{\circ} 55^{\prime} 39^{\prime \prime}$ & 1320 \\
\hline Sp26 & Salvia virgate Jacq. & Golestan, Ramian & $37^{\circ} 09^{\prime} 45^{\prime \prime}$ & $55^{\circ} 55^{\prime} 39^{\prime \prime}$ & 1320 \\
\hline Sp27 & Salvia nemorosa $\mathrm{L}$. & Mazandaran, Chalos & $36^{\circ} 14^{\prime} 14^{\prime \prime}$ & $51^{\circ} 18^{\prime} 07^{\prime \prime}$ & 1807 \\
\hline Sp28 & Salvia urmiensis Bunge & Kurdistan, Sanandaj & $35^{\circ} 20^{\prime} 53^{\prime \prime}$ & $53^{\circ} 30^{\prime} 20^{\prime \prime}$ & 2344 \\
\hline Sp29 & Salvia oligphylla Aucher ex Benth. & Ghazvin to Hamedan just after Avaj & $35^{\circ} 36^{\prime} 93^{\prime \prime}$ & $51^{\circ} 27^{\prime} 90^{\prime \prime}$ & 2100 \\
\hline Sp30 & Salvia verticillata $\mathrm{L}$. & Mazandaran Jadeh Chalous & $36^{\circ} 14^{\prime} 14^{\prime \prime}$ & $51^{\circ} 18^{\prime} 07^{\prime \prime}$ & 1807 \\
\hline
\end{tabular}




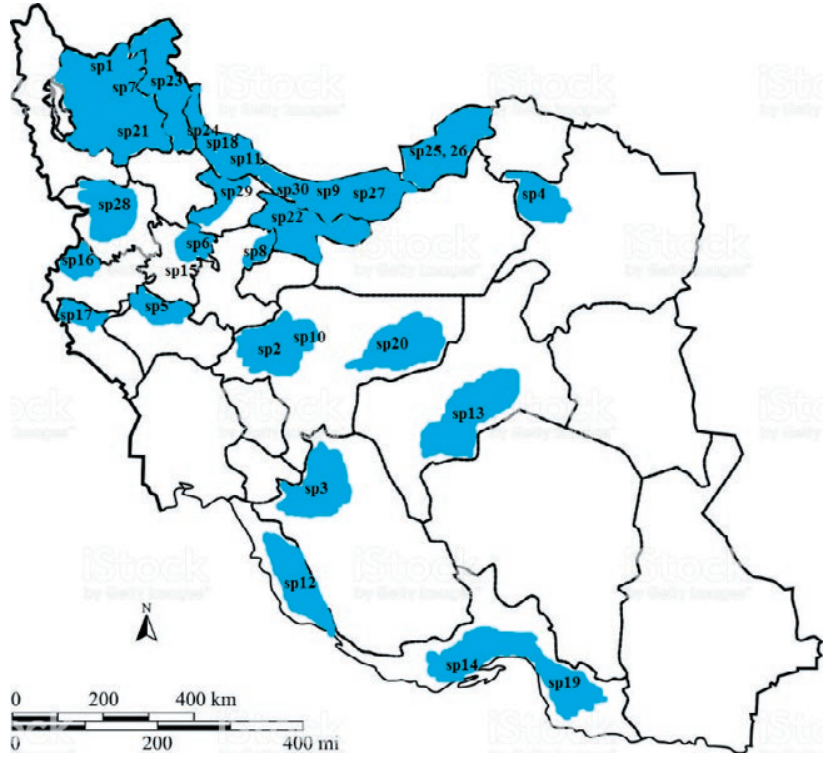

Figure 1. Map of Iran showing sampling localities for Salvia. sp1= Salvia aristata; $\mathrm{sp} 2=$ S. eremophila $; \mathrm{sp} 3=$ S. santolinifolia $; \mathrm{sp} 4=S$. tebesana; $\mathrm{sp} 5=S$. bracteata $; \mathrm{sp} 6=S$. suffruticosa; $\mathrm{sp} 7=S$. dracocephaloides; $\mathrm{sp} 8=$ S. hydrangea; $\mathrm{sp} 9=$ S. multicaulis; $\mathrm{sp} 10:$ S. syriaca; sp11: S. viridis; $\mathrm{sp} 12=S$. mirzayanii $; \mathrm{sp} 13=S$. macrosiphon; $\mathrm{sp} 14=$ S. sharifi $; \mathrm{sp} 15=S$. reuterana $; \mathrm{sp} 16=S$. palaestina $; \mathrm{sp} 17=S$. sclareopsis; $\mathrm{sp} 18=$ S. spinose; $\mathrm{sp} 19=$ S. compressa $; \mathrm{sp} 20=$ S. sclarea $; \mathrm{sp} 21=$ S. aethiopis; $\mathrm{sp} 22=$ S. microstegia $; \mathrm{sp} 23=$ S. $x$ anthocheila $; \mathrm{sp} 24=S$. limbata; $\mathrm{sp} 25=$ S. chloroleuca $; \mathrm{sp} 26=$ S. virgate $; \mathrm{sp} 27=$ S. nemorosa; sp28=S. urmiensis; sp29=S. oligphylla; sp30=S. verticillata .

\section{DNA Extraction and RAPD Assay}

In each of the populations studied, fresh leaves from one to twelve plants were used randomly. Leaves were dried with silica gel prior to DNA extraction (EsfandaniBozchaloyi et al. 2019). By running on 0.8 percent agarose gel, the quality of extracted DNA was examined. A total of 25 Operon Technology Decamer RAPD Primers (Alameda, Canada) belonging to OPA, OPB, OPC, OPD sets were used. Among them, ten primers were selected with simple, enlarged and rich bands of polymorphism (Table 2). PCR reactions were performed in a $25 \mu \mathrm{l}$ volume mixture containing the following component: Tris- $\mathrm{HCl}$ buffer $(10 \mathrm{mM})$ at $\mathrm{pH} 8 ; \mathrm{KCl}(50 \mathrm{mM}) ; \mathrm{MgCl}_{2}$ $(1.5 \mathrm{mM})$; dNTPs $(0.2 \mathrm{mM})$; primer $(0.2 \mu \mathrm{M})$; genomic DNA (20 ng) and of Taq DNA polymerase (3 U). In Techne thermocycler (Germany), the amplification reactions were carried out with the following PCR settings: 5 min initial denaturation at $94^{\circ} \mathrm{C} ; 40$ cycles of 1 min at $94{ }^{\circ} \mathrm{C} ; 1 \mathrm{~min}$ at $52-57^{\circ} \mathrm{C}$ and $2 \mathrm{~min}$ at $72{ }^{\circ} \mathrm{C}$. The reaction was completed by $7-10 \mathrm{~min}$ extension at $72^{\circ} \mathrm{C}$. The PCR amplified products were detected by running on $1 \%$ agarose gel, preceded by staining with ethidium bromide. The size of fragments was measured using a ladder with a molecular size of $100 \mathrm{bp}$ (Fermentas, Germany).

\section{DATA ANALYSES}

\section{Morphological studies}

Morphological characters $($ Mean $=0$, Variance $=$ 1) were first standardized and used to determine the Euclidean distance between taxa pairs (Podani 2000). The ordination methods of UPGMA (Unweighted paired group using average) were used for clustering the samples (Podani 2000). In order to demonstrate morphologi-

Table 2. RAPD primers used for this study and the extent of polymorphism.

\begin{tabular}{lcccccccc}
\hline Primer name & Primer sequence (5'-3') & TNB & NPB & PPB & PIC & PI & EMR & MI \\
\hline OPA-05 & 5'-AGGGGTCTTG-3' & 12 & 12 & $100.00 \%$ & 0.46 & 3.86 & 10.55 \\
OPA-06 & 5'-GGTCCCTGAC-3' & 9 & 8 & $84.99 \%$ & 0.33 & 4.51 & 8.43 & 2.85 \\
OPB-01 & 5'-GTTTCGCTCC-3' & 9 & 9 & $100.00 \%$ & 0.44 & 3.34 & 10.55 & 4.44 \\
OPB-02 & 5'-TGATCCCTGG-3' & 10 & 10 & $100.00 \%$ & 0.47 & 3.18 & 9.56 & 2.65 \\
OPC-04 & 5'-CCGCATCTAC-3' & 11 & 11 & $100.00 \%$ & 0.35 & 5.23 & 8.23 \\
OPD-02 & 5'-GGACCCAACC-3' & 14 & 13 & $93.74 \%$ & 0.47 & 4.66 & 8.56 & 3.67 \\
OPD-03 & 5'-GTCGCCGTCA-3' & 13 & 12 & $92.31 \%$ & 0.44 & 4.21 & 6.60 \\
OPD-05 & 5'-TGAGCGGACA-3' & 13 & 13 & $100.00 \%$ & 0.47 & 4.32 & 9.55 \\
OPD-08 & 5'-GTGTGCCCCA-3' & 11 & 9 & $82.89 \%$ & 0.33 & 6.56 & 9.34 \\
OPD-11 & 5'-AGCGCCATTG-3' & 10 & 10 & $100.00 \%$ & 0.49 & 4.25 & 11.11 \\
\hline Mean & & 11.2 & 10.7 & $93.68 \%$ & 0.44 & 4.6 & 3.87 \\
Total & & 112 & 107 & & & & 9.3 \\
\hline
\end{tabular}

Note: TNB - the number of total bands, NPB: the number of polymorphic bands, PPB (\%): the percentage of polymorphic bands, PI: polymorphism index, EMR, effective multiplex ratio; MI, marker index; PIC, polymorphism information content for each of CBDP primers. 
cal variation between populations, ANOVA (Analysis of variance) was performed, while PCA (Principal Components Analysis) bi-plot was employed to identify the most variable characters (Podani 2000). PAST software version 2.17 (Hammer et al. 2012) was used for multivariate statistical analyses of morphological data.

\section{Molecular analyses}

The obtained RAPD bands were coded as binary characters (absence $=0$, presence $=1$ ) and used for the study of genetic diversity (Powell et al. 1996; Heikrujam et al. 2015). For each primer, the number of polymorphic bands (NPB) was determined followed by the effective multiplex ratio (EMR). Other parameters such as Nei's gene diversity $(\mathrm{H})$, Shannon information index (I), number of effective alleles, and percentage of polymorphism ( $\mathrm{P} \%=$ number of polymorphic loci/number of total loci) were also determined (Weising et al, 2005; Freeland et al. 2011). The formula for calculation of Shannon's index was: $\mathrm{H}^{\prime}=-\Sigma$ piln pi. $\mathrm{Rp}$ is defined per primer as: $\mathrm{Rp}=\sum \mathrm{Ib}$, where "Ib" is the band informativeness, that takes the values of 1-(2x [0.5-p]), being " $p$ " the proportion of each genotype containing the band. The percentage of polymorphic loci, UHe, H' and PCA were determined by GenAlEx 6.4 software (Peakall and Smouse 2006). For generating Neighbor Joining (NJ) clusters and Neighbor-Net networking, Nei's genetic distance between populations was employed (Freeland et al. 2011; Huson and Bryant 2006). The Mantel test determined the correlation between the geographical and genetic distances of the populations (Podani 2000). These tests were performed in PAST ver. 2.17 (Hammer et al. 2012) and DARwin software ver. 5 (2012). As implemented in GenAlex 6.4 (Peakall \& Smouse, 2006), the AMOVA (Analysis of Molecular Variance) test (with 1000 permutations) was used to evaluate population genetic differences. Gene flow was estimated by calculating Nm, an estimate of gene flow from Gst in PopGene ver. 1.32 (1997) as: $\mathrm{Nm}=0.5(1-$ Gst $) / G s t$. This method considers the equal amount of gene flow among all populations (Yeh et al. 1999).

\section{RESULTS}

\section{Species identity and relationships - Morphometry}

ANOVA test showed substantial differences ( $P$ $<0.01)$ between the studied species in quantitative morphological characteristics. PCA analysis was conducted to determine the most variable characters among the taxa analysed. It showed that over $77 \%$ of the overall variance was composed of the first three variables. Characters such as seed shape, calyx shape, calyx length, bract length and basal leaf shape have shown the highest association $(>0.7)$ in the first PCA axis with 55 per cent of total variance. Characters affecting PCA axis 2 and 3 respectively were seed colour, leaf surface, corolla length, filament length, nut width, basal leaf length. Different ordination and clustering methods generated similar results. Therefore, PCoA plot of morphological characters are presented here (Fig. 2). Samples of each species were separately grouped. This finding indicates that the studied species were divided into different classes by both quantitative and qualitative morphological features. Among the studies sample we did not find any intermediate forms.

\section{Species identification and genetic diversity}

Ten RAPD primers were screened in order to study genetic relationships within Salvia. All primers generated reproducible polymorphic bands in 30 Salvia species. Figure 3 shows an image of the amplification of the RAPD created by the OPD-03 primer. In total, 107 amplified polymorphic bands were produced across 30 species. The size range of the amplified fragments was 150 to $3000 \mathrm{bp}$. The highest and lowest numbers of polymorphic bands were 13 for OPD-02, OPD-05 and 8 for OPA-06, with an average of 10.7 polymorphic bands per primer. The PIC of the 10 RAPD primers ranged from 0.32 (OPD-08) to 0.48 (OPD-011) with an average of 0.44 per primer. MI of the primers ranged from 2.11 (OPD08 ) to 5.47 (OPC-04) with an average of 3.5 per primer. EMR of the RAPD primers ranged from 6.60 (OPD-03) to 11.11 (OPD-011) with an average of 9.3 per primer (Table 2). The primers with the high EMR values were considered to be more informative in distinguishing the genotypes.

Genetic parameters were determined for all the 30 Salvia species amplified with RAPD primers (Table 3). The range of Unbiased expected heterozygosity $(H)$ was 0.099 (Salvia limbata) to 0.31 (S. reuterana) (mean: 0.18). A similar trend was depicted by Shannon's information index $(I)$, with the highest value of 0.39 found in $S$. reuterana and the lowest value of 0.13 found in S. limbata (mean: 0.27$)$. The observed number of alleles $(\mathrm{Na})$ varied between 0.201 in S. nemorosa and 1.28 in S. eremophila. The range of effective number of alleles $(\mathrm{Ne})$ was $1.00(S$. nemorosa) to 1.670 (S. santolinifolia).

AMOVA test revealed substantial genetic variation $(\mathrm{P}=0.01)$. It showed that $81 \%$ of total variation was interspecific and 19\% was intra-specific (Table 4). In 


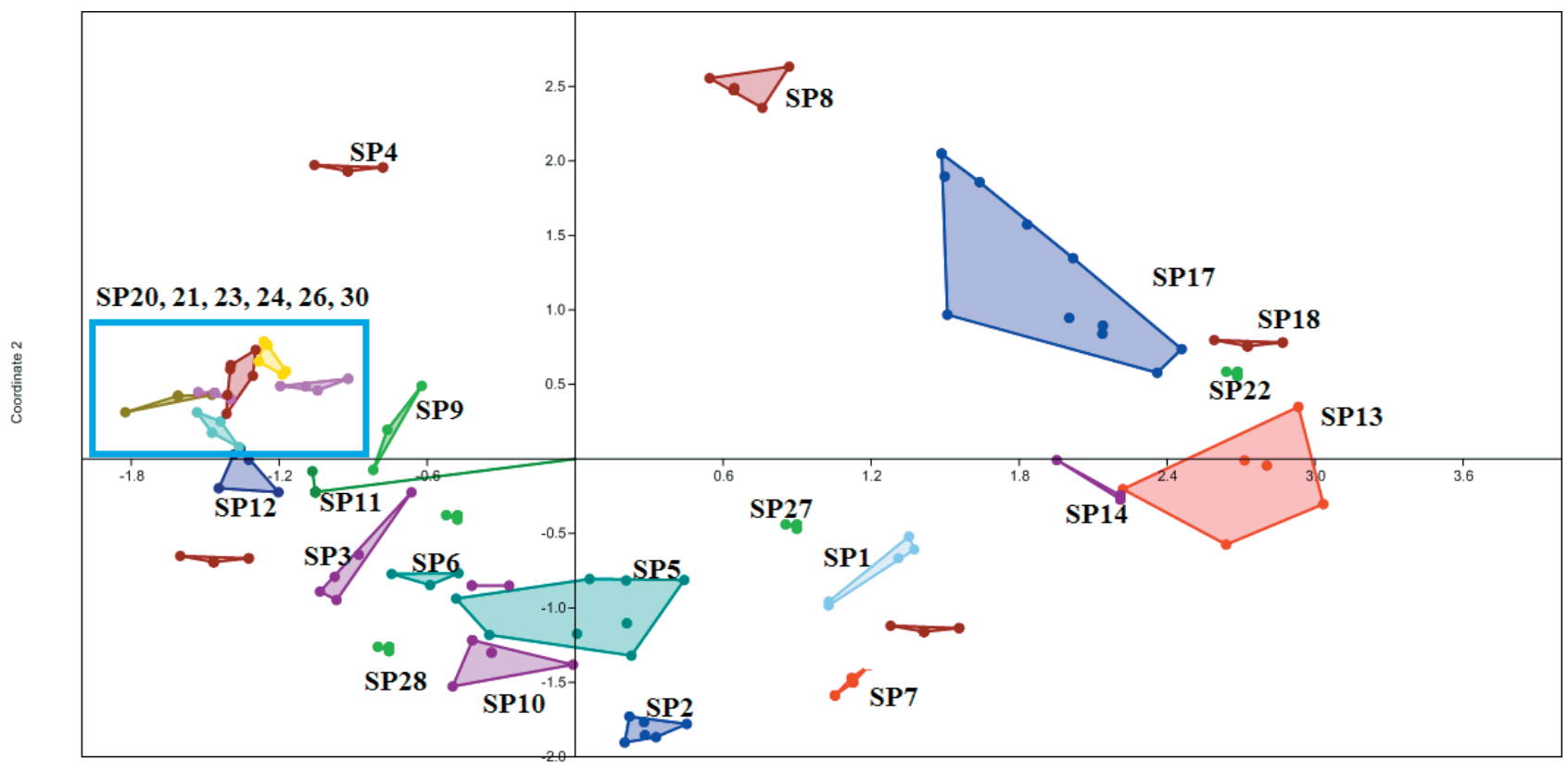

Coordinate 1

Figure 2. PCoA plots of morphological characters revealing species delimitation in the Salvia. $\mathrm{sp} 1=$ Salvia aristata; $\mathrm{sp} 2=$ S. eremophila; $\mathrm{sp} 3=$ S. santolinifolia; $\mathrm{sp} 4=$ S. tebesana; $\mathrm{sp} 5=$ S. bracteata $; \mathrm{sp} 6=$ S. suffruticosa; $\mathrm{sp} 7=$ S. dracocephaloides; $\mathrm{sp} 8=$ S. hydrangea; $\mathrm{sp} 9=$ S. multicaulis; sp10: S. syriaca; $\mathrm{sp11}$ : S. viridis; $\mathrm{sp12}=$ S. mirzayanii; $\mathrm{sp13}=$ S. macrosiphon; $\mathrm{sp} 14=$ S. sharifi; $\mathrm{sp} 15=$ S. reuterana; $\mathrm{sp} 16=S$. palaestina; $\mathrm{sp17}=$ S. sclareopsis; $\mathrm{sp} 18=$ S. spinose $; \mathrm{sp} 19=$ S. compressa; $\mathrm{sp} 20=$ S. sclarea $; \mathrm{sp} 21=$ S. aethiopis; $\mathrm{sp} 22=$ S. microstegia; $\mathrm{sp} 23=$ S. $x a$ anthocheila $; \mathrm{sp} 24=$ S. limbata $; \mathrm{sp} 25=$ S. chloroleuca $; \mathrm{sp} 26=$ S. virgate; $\mathrm{sp} 27=$ S. nemorosa $; \mathrm{sp} 28=$ S. urmiensis; $\mathrm{sp} 29=$ S. oligphylla; $\mathrm{sp} 30=$ S. verticillata .

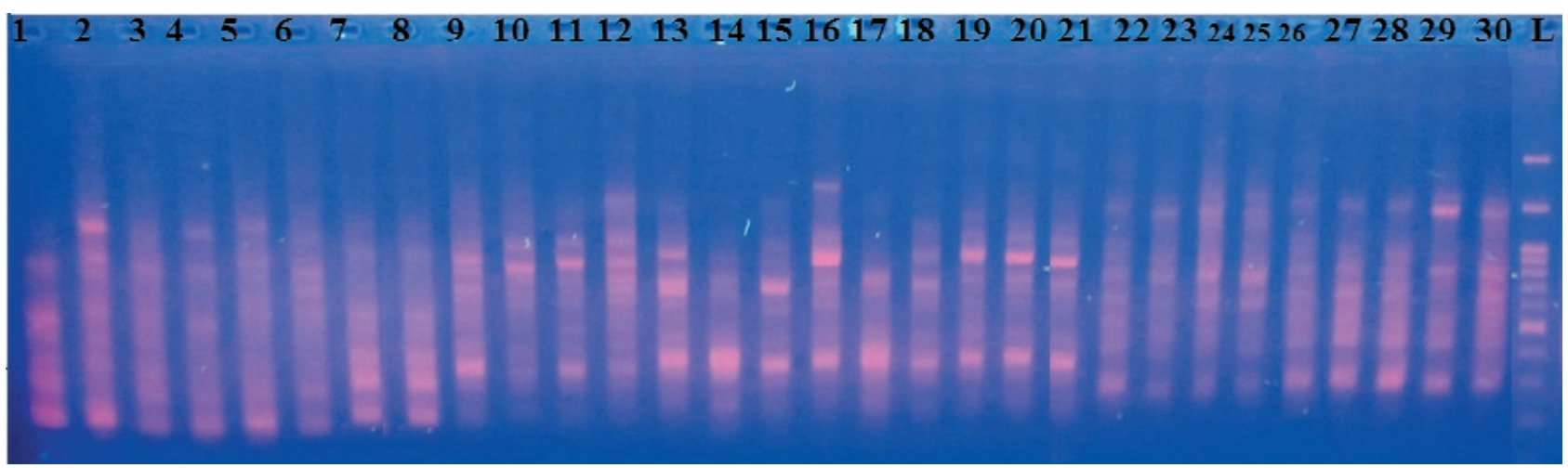

Figure 3. Electrophoresis gel of studied ecotypes from DNA fragments produced by OPD-03. $1=$ Salvia aristata; $2=$ S. eremophila; $3=$ S. santolinifolia; $4=$ S. tebesana; $5=S$. bracteata $; 6=$ S. suffruticosa; $7=$ S. dracocephaloides $; 8=$ S. hydrangea; $9=$ S. multicaulis; $10: S$. syriaca $; 11$ : S. viridis; $12=$ S. mirzayanii; $13=S$. macrosiphon; $14=S$. sharifi $; 15=$ S. reuterana $; 16=$ S. palaestina $; 17=S$. sclareopsis $; 18=S$. spinose $; 19=S$. compressa; $20=$ S. sclarea $; 21=$ S. aethiopis; $22=$ S. microstegia $23=$ S. xanthocheila $; 24=$ S. limbata $25=$ S. chloroleuca $; 26=S$. virgate $; 27=S$. nemorosa; $28=$ S. urmiensis; $29=$ S. oligphylla; $30=$ S. verticillata $; \mathrm{L}=$ Ladder $100 \mathrm{bp}$, Arrows are representative of polymorphic bands.

addition, genetic differentiation of was demonstrated by significant Nei's GST $(0.29, \mathrm{P}=0.001)$ and D_est values (0.137, $\mathrm{P}=0.01)$. Compared to intra-species, these results revealed a greater distribution of interspecific genetic diversity.

Two main clusters were produced in the NJ tree (Fig. 4). The first main cluster comprised two sub-clusters:
S. xanthocheila and S. verticillata were separated from the rest of the species and join the others with a great distance and comprised the first sub-cluster. The second sub-cluster comprised of S. limbata, S. aethiopis, S. sclarea and $S$. virgata. The second main cluster also comprised two sub-clusters: three species including $S$. sclareopsis, S. macrosiphon and S. sharifii were placed close 
Table 3. Genetic diversity parameters in the studied Salvia species.

\begin{tabular}{|c|c|c|c|c|c|c|c|}
\hline SP & $\mathrm{N}$ & $\mathrm{Na}$ & $\mathrm{Ne}$ & I & $\mathrm{He}$ & $\mathrm{UHe}$ & $\% \mathrm{P}$ \\
\hline S. aristata & 8.000 & 0.333 & 1.016 & 0.19 & 0.12 & 0.22 & $48.23 \%$ \\
\hline S. eremophila & 12.000 & 1.287 & 1.233 & 0.271 & 0.184 & 0.192 & $51.91 \%$ \\
\hline S. santolinifolia & 5.000 & 0.358 & 1.670 & 0.18 & 0.20 & 0.29 & $43.50 \%$ \\
\hline S. tebesana & 6.000 & 0.299 & 1.029 & 0.231 & 0.18 & 0.23 & $44.38 \%$ \\
\hline S. bracteata & 5.000 & 0.462 & 1.095 & 0.288 & 0.25 & 0.22 & $62.05 \%$ \\
\hline S. suffruticosa & 8.000 & 0.399 & 1.167 & 0.259 & 0.234 & 0.133 & $32.88 \%$ \\
\hline S. dracocephaloides & 8.000 & 0.477 & 1.187 & 0.256 & 0.233 & 0.148 & $31.26 \%$ \\
\hline S. hydrangea & 8.000 & 0.313 & 1.026 & 0.144 & 0.13 & 0.26 & $49.23 \%$ \\
\hline S. multicaulis & 12.000 & 1.144 & 1.322 & 0.28 & 0.284 & 0.192 & $50.91 \%$ \\
\hline S. syriaca & 5.000 & 0.358 & 1.117 & 0.28 & 0.15 & 0.12 & $44.30 \%$ \\
\hline S. viridis & 6.000 & 0.458 & 1.039 & 0.28 & 0.18 & 0.23 & $49.38 \%$ \\
\hline S. mirzayanii & 5.000 & 0.455 & 1.077 & 0.277 & 0.24 & 0.22 & $55.05 \%$ \\
\hline S. macrosiphon & 8.000 & 0.499 & 1.067 & 0.14 & 0.13 & 0.14 & $49.26 \%$ \\
\hline S. sharifii & 9.000 & 0.261 & 1.014 & 0.142 & 0.23 & 0.23 & $43.15 \%$ \\
\hline S. reuterana & 6.000 & 0.555 & 1.021 & 0.39 & 0.35 & 0.31 & $68.53 \%$ \\
\hline S. palaestina & 4.000 & 0.344 & 1.042 & 0.20 & 0.23 & 0.20 & $57.53 \%$ \\
\hline S. sclareopsis & 5.000 & 0.369 & 1.011 & 0.15 & 0.18 & 0.12 & $42.15 \%$ \\
\hline S. spinose & 9.000 & 0.261 & 1.014 & 0.142 & 0.33 & 0.23 & $43.15 \%$ \\
\hline S. compressa & 6.000 & 0.555 & 1.021 & 0.29 & 0.25 & 0.28 & $43.53 \%$ \\
\hline S. sclarea & 10.000 & 0.431 & 1.088 & 0.33 & 0.22 & 0.13 & $57.53 \%$ \\
\hline S. aethiopis & 3.000 & 0.255 & 1.021 & 0.15 & 0.18 & 0.12 & $42.15 \%$ \\
\hline S. microstegia & 3.000 & 0.288 & 1.024 & 0.23 & 0.15 & 0.17 & $44.30 \%$ \\
\hline S. xanthocheila & 9.000 & 0.352 & 1.083 & 0.23 & 0.22 & 0.14 & $45.05 \%$ \\
\hline S. limbata & 5.000 & 0.369 & 1.011 & 0.13 & 0.11 & 0.099 & $29.15 \%$ \\
\hline S. chloroleuca & 6.000 & 0.244 & 1.032 & 0.26 & 0.23 & 0.18 & $55.53 \%$ \\
\hline S. virgata & 4.000 & 0.314 & 1.044 & 0.16 & 0.18 & 0.23 & $43.38 \%$ \\
\hline S. nemorosa & 8.000 & 0.201 & 1.00 & 0.33 & 0.17 & 0.12 & $42.23 \%$ \\
\hline S. urmiensis & 5.000 & 0.341 & 1.058 & 0.24 & 0.27 & 0.20 & $53.75 \%$ \\
\hline S. oligphylla & 3.000 & 0.567 & 1.062 & 0.24 & 0.224 & 0.113 & $44.73 \%$ \\
\hline S. verticillata & 5.000 & 0.336 & 1.034 & 0.23 & 0.25 & 0.19 & $51.83 \%$ \\
\hline
\end{tabular}

Abbreviations: N: number of samples; Na: number of different alleles; Ne: number of effective alleles, I: Shannon's information index, He: gene diversity, UHe: unbiased gene diversity, $\mathrm{P} \%$ : percentage of polymorphism, populations.

Table 4. Analysis of molecular variance (AMOVA) of the studied species.

\begin{tabular}{lcccccc}
\hline Source & df & SS & MS & Est. Var. & $\%$ & $\Phi P T$ \\
\hline Among Pops & 28 & 1601.364 & 79.789 & 12.154 & $81 \%$ & $81 \%$ \\
Within Pops & 130 & 234.443 & 4.777 & 2.888 & $19 \%$ & \\
Total & 158 & 1955.777 & & 14.060 & $100 \%$ &
\end{tabular}

df: degree of freedom; SS: sum of squared observations; MS: mean of squared observations; EV: estimated variance; $\boldsymbol{\Phi P T}$ : proportion of the total genetic variance among individuals within an accession, $(\mathrm{P}<0.001)$.

to each other, while close genetic affinity between other species. Relationships obtained from RAPD data usually agree well with the relationship of species obtained from morphological data. This is in accordance with the parameters of AMOVA and genetic diversity previously reported. Salvia species are genetically well distinguished from each other. The species are well distinguished from each other genetically. These findings show that RAPD molecular markers can be used in the taxonomy of Salvia. The Nm analysis by Popgene software also produced mean $\mathrm{Nm}=0.288$, that is deemed a low value of gene flow. A strong association $(r=0.16$, $\mathrm{p}=0.0002$ ) between genetic- and geographical distance was demonstrated by Mantel test with 5000 permutations. It indicates that isolation by distance (IBD) has occurred among these species.

The results of Nei's genetic identity and the genetic distance (Table 5) show the highest genetic similarity 


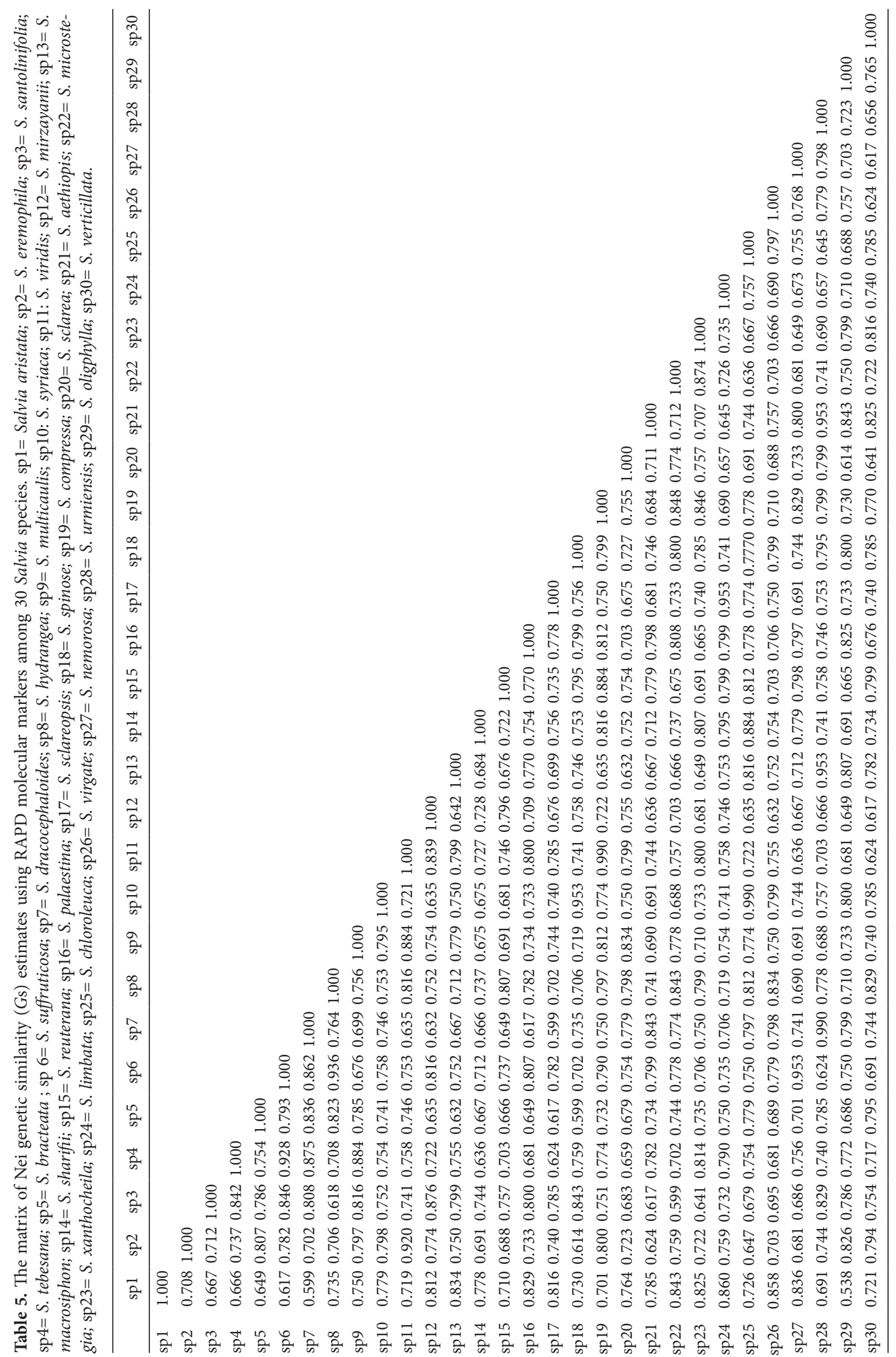




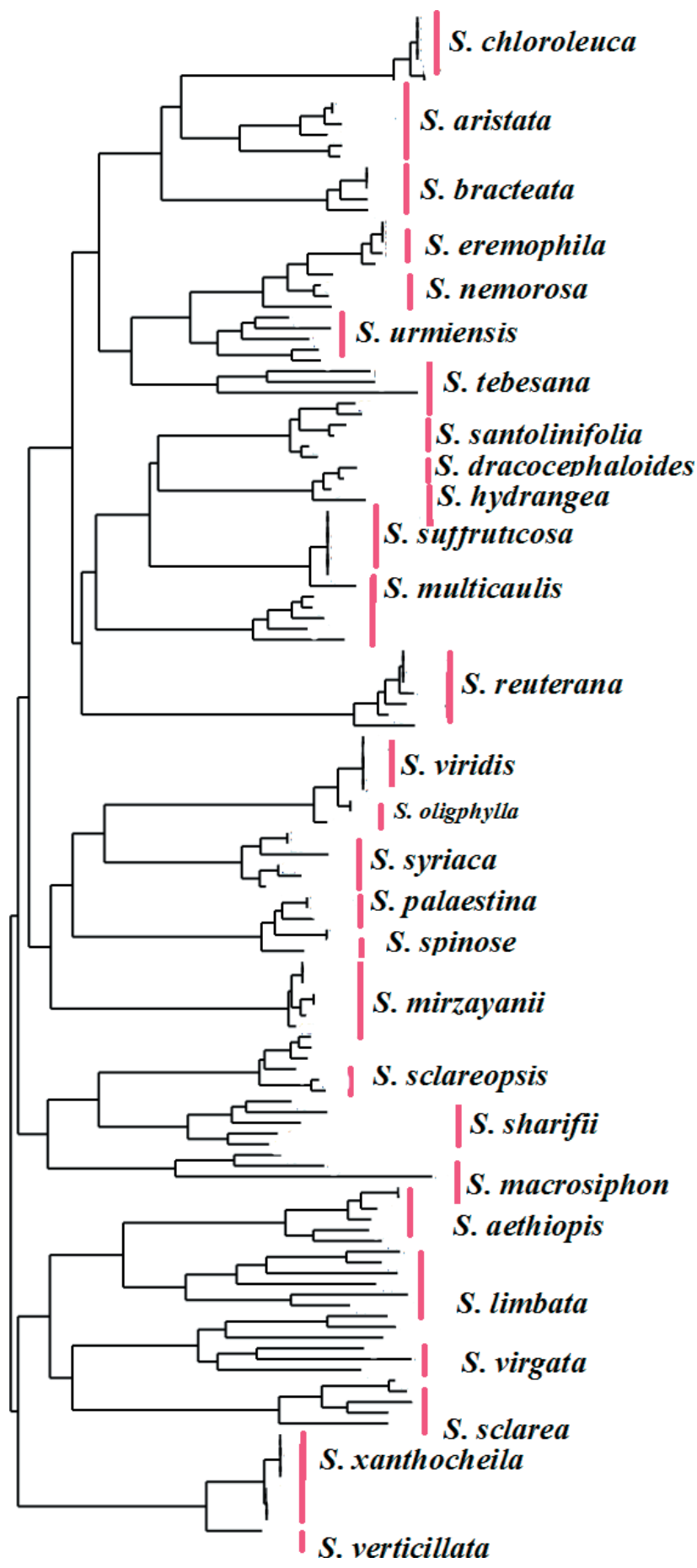

Figure 4. NJ tree of RAPD data revealing species delimitation in the Salvia.

(0.93) between S. suffruticosa and S. Hydrangea. Lowest of genetic similarity was shown between $S$. aristata and S. oligphylla (0.53). Lower Nm value (0.288) is an indicator of limited gene flow or ancestrally shared alleles between different species and indicating high genetic differentiation among and within Salvia species.

\section{DISCUSSION}

Genetic diversity is a fundamental element of biodiversity and its conservation is indispensable for longterm survival of any species in unstable environments (Mills and Schwartz 2005; Tomasello et al. 2015). Genetic diversity is non-randomly distributed among different populations and is influenced by numerous factors such as geography, dispersal mechanisms, breeding systems, life span etc. Changes in environment often lead to variation in genetic diversity levels among populations, and under adverse circumstances, populations with little variability are generally deemed less adapted (Falk and Holsinger 1991; Olivieri et al. 2016). Most authors recognize that genetic diversity is fundamental to preserving the long-term evolutionary potential of a species (Falk and Holsinger 1991). Experimental and field research has shown that habitat fragmentation and population decline have reduced the effective population size in the last decade. Similarly, majority of geneticists regard population size as a significant factor in preserving genetic variation (Turchetto et al. 2016). In fragmented populations, this is very important because it is more vulnerable because of allelic richness loss and increased population differentiation via genetic drift and inbreeding depression (Frankham 2005). Information of inter- and intra-population genetic diversity is therefore important for their conservation and management (e.g. EsfandaniBozchaloyi et al. 2018a, 2018b, 2018c, 2018d).

We used morphological and molecular RAPD molecular data to test species relationships in Salvia in the current analysis. Morphological studies showed that both quantitative (the ANOVA test result) and qualitative characters are well distinguished from each other (The PCA plot result). Furthermore, PCA analysis suggests that morphological characters such as bract length, stipule length, bract shape, calyx shape, petal shape, stem-leaf length and width, petal length and width may be used in the delimitation of species groups. This morphological differentiation is attributed to quantitative and qualitative characters.

\section{Genetic structure and gene flow}

A primer's PIC and MI characteristics assist in assessing its usefulness in the study of genetic diversity. Sivaprakash et al. (2004) asserted that the ability to overcome genetic diversity by a marker technique could be 
more explicitly linked to the degree of polymorphism. In general, the PIC value 0 to 0.25 suggests a very low genetic diversity among genotypes, a mid-level of genetic diversity (Tams et al. 2005). In this study, the RAPD primers' PIC values ranged from 0.33 to 0.49 , with a mean value of 0.44 , indicating a moderate level ability of RAPD primers in determining genetic diversity. Somewhat similar but low PIC values have been reported for ISSR and RAPD in Salvia species (Yousefiazar-Khanian et al. 2016); RAPD and AFLP in African plantain (Ude et al. 2003), AFLP in wheat (Bohn et al. 1999) and SCoT markers (Etminan et al. 2018; Pour-Aboughadareh et al. 2017, 2018). In Heikrujam et al. (2015), CBDP markers were shown to be more efficient than SCoT regarding the average PIC which was higher. In our analysis, the RAPD markers reflect success in estimating genetic diversity of Salvia species regarding average percentage polymorphism (93.68\%), average PIC value of RAPD markers (0.44), average MI (3.5) and average EMR of RAPD markers (9.3), which were higher than other reported markers on Salvia (Wang et al. 2009; Song et al. 2010; Yousefiazar-Khanian et al. 2016; Etminan et al. 2018; Souframanien and Gopalakrishna 2004). Gene flow is inversely correlated with the gene differentiation but is very significant for population evolution, and occurs through pollen grains and seeds between populations (Song et al. 2010). The observed gene flow (Nm) between Salvia species was 0.288 in the current study, indicating low genetic differentiation.

Generally, the pollinators of Old World Salvia are insects (Claßen-Bockhoff et al. 2004). At the lower elevations, bees and at the higher altitudes insects such as flies are the major pollinators of bi-labiate flowers such as Salvia (Pellissier et al. 2010).

According to Moein et al., (2019) SRAP marker's genetic structure revealed that despite the existence of limited gene flow, two separate ecotypes were produced which may be the result of reproductive isolation triggered by altitudinal gradient and dissimilar niches through parapatric speciation (Que et al. 2014). In conclusion, the findings of this study showed that the primers derived from RAPD were more efficient than the other molecular markers in assessing the genetic diversity of Salvia in Iran. In addition, the Salvia species in the dendrogram and PCoA were clearly distinguished from each other, suggesting the greater efficiency of the RAPD technique in the identification of the genus.

\section{ACKNOWLEDGMENT}

The authors thank anonymous reviewers for valuable comments on an earlier draft.

\section{REFERENCES}

Bohn M, Utz HF, Melchinger AE.1999. Genetic similarities among wheat cultivars determined on the basis of RFLPs, AFLPs and SSRs and their use for predicting progeny variance. Crop Sci. 39: 228-237.

Cires E, Cuesta C, Fernández Prieto JA. 2012. Conservation genetics of the endangered endemic Ranunculus cabrerensis subsp. muniellensis (Ranunculaceae) in the Northwest of Spain. Bol. Ci. Nat. RIDEA 52: 117134.

Cires E, Cuesta C, Fernández Prieto JA. 2013. Genetic diversity and structure in fragmented populations of the endangered species Ranunculus cabrerensis (Ranunculaceae): implications for conservation. Biologia 68(1): 30-40.

Chen SY, Dai TX, Chang YT, Wang SS, Ou SL, Chuang WL, Cheng CY, Lin YH, Lin LY, Ku HM 2013. Genetic diversity among Ocimum species based on ISSR, RAPD and SRAP markers. Australian Journal of Crop Science 7(10): 1463-1471.

Claßen-Bockhoff R, Speck T, Tweraser E, Wester P, Thimm S, Reith M. 2004. The staminal lever mechanism in Salvia L. (Lamiaceae): a key innovation for adaptive radiation? Org. Divers. Evol. 4(3): 189-205. https://doi.org/10.1016/j.ode.2004.01.004

Erbano M, Schnell e Schühli G, Pereira dos Santos É. 2015. Genetic variability and population structure of Salvia lachnostachys: implications for breeding and conservation programs. Int. J. Mol. Sci. 16(4): 78397850. https://doi.org/10.3390/ijms16047839

Etminan A, Pour-Aboughadareh A, Nooric A. 2018. Genetic relationships and diversity among wild Salvia accessions revealed by ISSR and SCoT markers. Biotechnol. Biotechnol. Equip. 32: 610-617.

Esfandani-Bozchaloyi S, Sheidai M, Keshavarzi M, Noormohammadi Z. 2017a. Genetic Diversity and Morphological Variability In Geranium Purpureum Vill. (Geraniaceae) Of Iran. Genetika 49: 543-557. https:// doi.org/10.2298/GENSR1702543B

Esfandani-Bozchaloyi S, Sheidai M, Keshavarzi M, Noormohammadi Z. 2017b. Species Delimitation In Geranium Sect. Batrachioidea: Morphological And Molecular. Acta Botanica Hungarica 59(3-4): 319-334. doi: 10.1556/034.59.2017.3-4.3

Esfandani-Bozchaloyi S, Sheidai M, Keshavarzi M, Noormohammadi Z, 2017c. Genetic and morphological diversity in Geranium dissectum (Sec. Dissecta, Geraniaceae) populations. Biologia 72(10): 1121-1130. DOI: 10.1515/biolog-2017-0124

Esfandani-Bozchaloyi S, Sheidai M, Keshavarzi M, Noormohammadi Z 2017d. Analysis of genetic diversity in 
Geranium robertianum by ISSR markers. Phytologia Balcanica 23(2): 157-166.

Esfandani-Bozchaloyi S, Sheidai M, Keshavarzi M, Noormohammadi Z . 2018a. Species Relationship and Population Structure Analysis In Geranium Subg. Robertium (Picard) Rouy With The Use of ISSR Molecular Markers. Act Bot Hung, 60(1-2): 47-65.

Esfandani-Bozchaloyi S, Sheidai M, Keshavarzi M, Noormohammadi Z. 2018b. Species Identification and Population Structure Analysis In Geranium Subg. Geranium (Geraniaceae). Hacquetia 17(2): 235-246. DOI: 10.1515/hacq-2018-0007

Esfandani -Bozchaloyi S, Sheidai M, Keshavarzi M, Noormohammadi Z. 2018c. Morphometric and ISSR-analysis of local populations of Geranium molle L. from the southern coast of the Caspian Sea. Cytology and genetics 52(4): 309-321.

Esfandani-Bozchaloyi S, Sheidai M. 2018d. Molecular diversity and genetic relationships among Geranium pusillum and G. pyrenaicum with inter simple sequence repeat (ISSR) regions, Caryologia 71(4): 1-14. https://doi.org/10.1080/00087114.2018.1503500

Ellegren H, Galtier N. 2016. Determinants of genetic diversity. Nat. Rev. Genet. 17: 422-433.

Freeland JR, Kirk H, Peterson SD. 2011. Molecular Ecology (2nded). Wiley-Blackwell, UK, 449 pp.

Falk DA, Holsinger KE (Eds.). 1991. Genetics and conservation of rare plants. Oxford Univ. Press, New York.

Frankham R. 2005. Stress and adaptation in conservation genetics. J. Evol. Biol. 18: 750-755.

Gholamin, R. \& Khayatnezhad, M. 2020b. The effect of dry season stretch on Chlorophyll Content and RWC of Wheat Genotypes (Triticum Durum L.). Bioscience Biotechnology Research Communications 13: 1833-1829.

Gholamin, R. \& Khayatnezhad, M. 2020c. Study of Bread Wheat Genotype Physiological and Biochemical Responses to Drought Stress. Helix. 10: 87-92.

Gholamin, R. \& Khayatnezhad, M. 2020d. The Study of Path Analysis for Durum Wheat (Triticum durum Desf.) Yield Components. Bio. Biot. Res.Comm. 13: 2139-2144.

Huson DH, Bryant D. 2006. Application of Phylogenetic Networks in Evolutionary Studies. Molecular Biology and Evolution 23: 254-267.

Hammer O, Harper DA, Ryan PD. 2012. PAST: Paleontological Statistics software package for education and data analysis. Palaeonto Electro 4: 9.

Heikrujam M, Kumar J, Agrawal V. 2015. Genetic diversity analysis among male and female Jojoba genotypes employing gene targeted molecular markers, start codon targeted (SCoT) polymorphism andCAAT box-derived polymorphism (CBDP) markers. Meta Gene 5: 90-97.

Jamzad Z. 2012. Lamiaceae. - In: Assadi, M., Maassoumi, A. and Mozaffarian, V. (eds): Flora of Iran. Vol. 76. Research Institute of Forests and Rangelands, Tehran, $810 \mathrm{pp}$.

Jing, X., Wang, H., Huang, X., Chen, Z., Zhu, J.,... Wang, $X$. (2021). Digital image colorimetry detection of carbaryl in food samples based on liquid phase microextraction coupled with a microfluidic thread-based analytical device. Food chemistry, 337, 127971. doi: 10.1016/j.foodchem.2020.127971

Kharazian N, Rahimi S, Shiran B. 2015. Genetic diversity and morphological variability of fifteen Stachys (Lamiaceae) species from Iran using morphological and ISSR molecular markers. Biologia 70(4): 438-452.

Kharazian, N. 2010. TAXONOMY AND MORPHOLOGY OF SALVIA SPINOSA L. (LAMIACEAE) IN IRAN. J. Tax. Biosist, 1(1): 9-20. https://www.sid.ir/ en/journal/ViewPaper.aspx?id=177108

Khayatnezhad, M. \& Gholamin, R. 2021a. The Effect of Drought Stress on the Superoxide Dismutase and Chlorophyll Content in Durum Wheat Genotypes. Advancements in Life Sciences, 8: 119-123.

Khayatnezhad, M. \& Gholamin, R. 2021b. Impacts of Drought Stress on Corn Cultivars (Zea mays L.) At the Germination Stage. Bioscience Research, 18: 409414.

Mills M, Schwartz M. 2005. Rare plants at the extremes of distribution: broadly and narrowly distributed rare species. Biodivers. Conserv. 14: 1401-1420.

Niu, M., Lin, Y., \& Zou, Q. (2021). sgRNACNN: identifying sgRNA on-target activity in four crops using ensembles of convolutional neural networks. Plant molecular biology, 105(4-5), 483-495. doi: 10.1007/ s11103-020-01102-y

Olivieri I, Tonnabel J, Ronce O, Mignot A. 2016. Why evolution matters for species conservation: perspectives from three case studies of plant metapopulations. Evol. Appl. 9: 196-211.

Peakall R, Smouse PE. 2006. GENALEX 6: genetic analysis in Excel. Population genetic software for teaching and research. Molecular Ecology Notes 6: 288-295.

Pellissier L, Pottier J, Vittoz P, Dubuis A, Guisan A. 2010. Spatial pattern of floral morphology: possible insight into the effects of pollinators on plant distributions. Oikos 119(11): 1805-1813. https://doi.org/10.1111/ j.1600-0706.2010.18560.x

Podani J. 2000. Introduction to the Exploration of Multivariate Data English translation. Backhuyes publisher, Leide, 407 pp. 
Peng L, Ru M, Wang B, Wang Y, Li B, Yu J, Liang Z. 2014. Genetic diversity assessment of a germplasm collection of Salvia miltiorrhiza Bunge. based on morphology, ISSR and SRAP markers. Bio. Syst. Eco. 55: 84-92.

Powell W, Morgante M, Doyle JJ, McNicol JW, Tingey SV, Rafalski AJ. 1996. Gene pool variation in genus Glycine subgenus Soja revealed by polymorphic nuclear and chloroplast microsatellites. Genetics 144: 793-803.

Patel HK, Fougat RS, Kumar S, Mistry JG, Kumar M. 2014. Detection of genetic variation in Ocimum species using RAPD and ISSR markers. 3 Biotech 5(5): 697-707.

Pour-Aboughadareh A, Ahmadi J, Mehrabi A, Etminan A, Moghaddam M. 2017. Assessment of genetic diversity among Iranian Triticum germplasm using agro-morphological traits and start codon targeted (SCoT) markers. Cereal Res. Commun. 45: 574-586.

Pour-Aboughadareh A, Ahmadi J, Mehrabi A, Etminan A, Moghaddam M. 2018. Insight into the genetic variability analysis and relationships among some Aegilops and Triticum species, as genome progenitors of bread wheat, using SCoT markers. Plant Biosys. For. 152: 694-703.

Que Y, Pan Y, Lu Y, Yang C, Yang Y, Huang N. 2014. Genetic analysis of diversity within a Chinese local sugarcane germplasm based on start codon targeted polymorphism. Biomed Res. Int. 2014: 1-10.

Song Z, Li X, Wang H, Wang J. 2010. Genetic diversity and population structure of Salvia miltiorrhiza Bge in China revealed by ISSR and SRAP. Genetica 138(2): 241-249.

Sun, S., Xu, L., Zou, Q., Wang, G., \& Gorodkin, J. (2021). BP4RNAseq: a babysitter package for retrospective and newly generated RNA-seq data analyses using both alignment-based and alignment-free quantification method. Bioinformatics, 37(9), 1319-1321. doi: 10.1093/bioinformatics/btaa832

Sepehry Javan Z, Rahmani F, Heidari R. 2012. Assessment of genetic variation of genus Salvia by RAPD and ISSR markers. Aust. J. Crop. Sci. 6(6): 1068-1073.

Sivaprakash KR, Prasanth SR, Mohanty BP, Parida A. 2004. Genetic diversity of black gram landraces as evaluated by AFLP markers. Curr. Sci. 86: 1411-1415.

Souframanien J, Gopalakrishna T. 2004. A comparative analysis of genetic diversity in blackgram genotypes using RAPD and ISSR markers. Theor. Appl. Genet. 109: 1687-1693.

Tams SH, Melchinger AE, Bauer E. 2005. Genetic similarity among European winter triticale elite germplasms assessed with AFLP and comparisons with SSR and pedigree data. Plant Breed. 124: 154-160.

Tomasello S, Álvarez I, Vargas P, Oberprieler C. 2015. Is the extremely rare Iberian endemic plant spe- cies Castrilanthemum debeauxii (Compositae, Anthemideae) a 'living fossil'? Evidence from a multi-locus species tree reconstruction. Mol. Phylogenet. Evol. 82: 118-130.

Turchetto C, Segatto ALA, Mäder G, Rodrigues DM, Bonatto S, Freitas LB. 2016. High levels of genetic diversity and population structure in an endemic and rare species: implications for conservation. AoB Plants 8: plw002.

Ude G, Pillay M, Ogundiwin E. 2003. Genetic diversity in an African plantain core collection using AFLP and RAPD markers. Theor Appl Genet 107: 248-255.

Will M, Claßen-Bockhoff R. (2017) Time to split Salvia s.l. (Lamiaceae) - new insights from Old World Salvia phylogeny. Molecular Phylogenetics and Evolution 114: 33-58.

Wang M, Li J, Zhang L, Yang RW, Ding CB, Zhou YH, Yin ZQ. 2011. Genetic diversity among Salvia miltiorrhiza Bunge and related species using morphological traits and RAPD markers. Journal of Medicinal Plants Research 5(13): 2687-2694.

Wang B, Zhang Y, Chen CB, Li XL, Chen RY, Chen L 2007. Analysis on genetic diversity of different Salvia miltiorrhiza geographical populations in China. Chin. Med. J. 32: 1988-1991.

Wang O, Zhang B, Lu L. 2009. Conserved region amplification polymorphism (CoRAP), a novel marker technique for plant genotyping in Salvia miltiorrhiza. Plant Mol. Biol. Rep. 27: 139-143.

Weising K, Nybom H, Wolff K, Kahl G. 2005. DNA Fingerprinting in Plants. Principles, Methods, and Applications. 2nd ed. CRC Press, Boca Rayton, 472 pp.

Walker JB, Sytsma KJ, Treutlein J, Wink M. 2004. Salvia (Lamiaceae) is not monophyletic: implications for the systematics, radiation, and ecological specializations of Salvia and tribe Mentheae. Amer. J. Bot. 91(7): 1115-1125. https://doi.org/10 .3732/ajb.91.7.1115

Williams J. G. K., Kubelik A. R., Livak K. J., Rafalski J. A., Tingey S. V. 1990. DNA polymorphisms amplifi ed by arbitrary primers are useful as genetic markers. Nucleic Acids Res 18: 6531-6535.

Yeh FC, Yang R, Boyle T 1999. POPGENE. Microsoft Windows-based freeware for population genetic analysis. Release 1.31. University of Alberta 1-31.

Yousefiazar-Khanian M, Asghari A, Ahmadi J. 2016. Genetic diversity of Salvia species assessed by ISSR and RAPD markers. Not. Bot. Horti. Agrobo. 44: 431-436.

Zou, Q., Xing, P., Wei, L., \& Liu, B. (2019). Gene2vec: gene subsequence embedding for prediction of mammalian N 6 -methyladenosine sites from mRNA. RNA (Cambridge), 25(2), 205-218. doi: 10.1261/ rna.069112.118 